\title{
On the relevance of the mathematics curriculum to young people
}

Paula Sealey \& Andrew Noyes

\begin{abstract}
In this paper we draw upon focus group data from a large study of learner trajectories through 14-19 mathematics education to think about the notion of relevance in the mathematics curriculum. Drawing on data from three socially distanced sites we explore how different emphases on what might be termed practical, process and/or professional forms of relevance affect the experiences and aspirations of learners of mathematics. We consider whether an emphasis on practical relevance in schools serving relatively disadvantaged communities might aid the reproduction of students' social position. This leads us to suggest that a fourth category of curriculum relevance - political relevance is largely missing from classrooms.
\end{abstract}

Keywords: Mathematics education, A level, participation, relevance, mixed methods

\section{Introduction}

Recently, Onion (2004) reported that many 14-16 year olds thought that the mathematics they were taught at school was useful only in mathematics lessons and for exams. Displaying a good understanding if the situated-ness of learning (Lave \& Wenger, 1991) they could not see the relevance of school mathematics to their current or future lives outside school. Whilst there was a broad consensus that basic mathematics was useful in everyday life they had mixed views regarding the usefulness of mathematics in their anticipated future work place environments. In general, the extent to which students thought that mathematics would be useful in their future careers (in the work place) depended upon which school they attended, rather than on their career aspirations. This suggests that students' attitudes toward mathematics are based upon guidance from teachers, rather than from direct knowledge of the use of mathematics in adult working lives. More recently Musto (2008) has also argued that students, and not 
just disaffected ones, fail to see the relevance of mathematics and how it would be used in everyday life.

We do not believe that the only reason for teaching mathematics is its future relevance (see for example, Ernest, 2004; Noyes, 2007, 2009) but in the current climate of functional skills and increasingly utilitarian rationale for the curriculum we want to explore in this paper how young people perceive the relevance of their school mathematics. We will also consider how these perceptions might influence learner trajectories in mathematics. In considering the notion of relevance we argue that the meaning of this term varies between social groups. Brown et al's (2008) survey of students found that whilst some students with higher predicted GCSE grades tended to feel that mathematics was prestigious, well-regarded by universities and useful to support other subjects, other students felt that mathematics was a waste of time as they were unlikely to ever use much of the mathematics they had recently learned.

Building on these studies we want to explore three factors which we consider to be important in discussing relevance of mathematics to learners: 1 ) school context; 2) the departmental culture and pedagogy (which is not independent from the school context) and 3) the different meanings that 'relevance' has for different students. Our data suggests three different categories of relevance, (a) usefulness (practical relevance), (b) transferable skills (process relevance) and (c) exchange value (professional relevance). Students in different schools with broadly different educational and career aspirations have different notions of relevance. We want to problematise the notion of relevance and suggest that it is related to cultural capital and social position. In order to explore this claim we discuss three vignettes of varying lengths from focus group discussions in three very different schools.

Our data comes from the Geographies of Mathematical Attainment and Participation (GMAP) Project. The GMAP project is a longitudinal, multi-layered, mixed-methods study exploring regional patterns of mathematics attainment and participation and the roles of 
families, peers, teachers and schools in constructing these patterns. With a particular concern for social justice the project explores who gets to do what mathematics and where. The four layers of the study are:

1. Statistical analyses (descriptive, multilevel modelling) of attainment and social data from the National Pupil Database, focused on 16 and 18 year olds in the Midlands of England from 2004-2008.

2. Mapping of the results from Layer 1 using Geographic Information Systems technology to explore the role of place in attainment and participation.

3. Questionnaire surveys of students in Year 7, 11 and 12 and mathematics teachers in a sample of sixteen secondary schools (covering the age range 11-18) in one part of the Midlands.

4. School case studies tracking Year 11 and 12 cohorts in half of the schools from Layer 3 to include teacher interviews, focus groups and some lesson observation.

\section{Focus Groups}

We draw on qualitative data from student focus groups (Wilson, 1997) to explore the issue of participation/non-participation in Advanced level (A level) and the role that notions of relevance might have to student decisions. Two focus group discussions with teacher-selected samples of year 10 students (who were then tracked into year 11) were carried out in eight of the sixteen schools (116 students in total). The schools serve a range of types of catchment and, therefore, the students interviewed come from very different social backgrounds. Participants in the focus groups had to be (a) capable of achieving $6^{\text {th }}$ form entry - usually 5 GCSE $A^{*}-C$ and possibly a $B$ grade or above in mathematics if wishing to study mathematics A level, and (b) thought capable of undertaking A level mathematics. We were particularly interested in the marginal students i.e. those who were not firmly decided on studying A level mathematics but who could be persuaded either way depending upon their performance and experience of GCSE mathematics. It is from this group that increased A level participation might arise. 
The focus group discussions were carried out during the spring term of 2009 when the students were in Year 11. A set of prompt questions were used to get them discussing their experiences of, and aspirations in, mathematics. Recordings of these interviews were transcribed and coded in Nvivo. Student names have been anonymised.

In exploring this data we are interested in a number of issues. Here we want to focus on different notions of relevance and how these might have varied effects for socially distanced students. As we will try and demonstrate, it is problematic that students from the high attaining suburban school see the relevance of mathematics qualifications in its exchange value whilst students in relatively disadvantaged communities have far less understanding of the hierarchy of academic subjects. This latter group tend to express far more insightful views of a mathematised society (Gellert \& Jablonka, 2008) but seem to be subject to its power, partly due to the kinds of careers they aspire to and in which they see their family and neighbours engaged.

In order to explore these issues we want to compare data extracts from three of our case studies: Larkstone; Chattingham and Deneswood. There is only space here to include short excerpts and as already noted we give very different amounts of space to each site. The data is used to support our broader argument which is developed from a very large dataset.

Larkstone School is a large, 11-18, mixed sex, comprehensive in a former coal mining community in the Midlands. It is a specialist Mathematics and Computing College. The majority of the 1,100 students are white British with only a few students from minority ethnic groups. Students have a range of socio-economic backgrounds but are predominantly from highly deprived areas in the locality. There is a higher than average percentage of students eligible for free school meals. If students do progress to higher education then they tend to be the first generation within their families to do so. The school operates a fast-track system for Mathematics GCSE with the most able students 
sitting this qualification at the end of Year 10. The mathematics department is considered very 'effective' (in the school effectiveness tradition) and is led by a strong teacher who grew up in a similar community and is firmly committed to giving any student the opportunity to study A level mathematics. Below we consider two discussions: one between Joe and Nathan, and one between Leanne, Kieran and Stuart. All five achieved Mathematics GCSE at the end of Year 10 and are now studying Statistics GCSE in Year 11. Not one student intends to take A level mathematics in the sixth form. We do not get into discussing the impact of early entry for GCSE in year 10 but acknowledge that this increasing practice (Noyes, Wake, Drake, \& Murphy, 2009) probably has had a detrimental impact on these students' attitudes.

Chattingham School is a large, $11-18$, mixed sex, comprehensive in the Midlands. It is a specialist Sports college and it shares a sixth form with a neighbouring school. Of its 1,200 students just over one-half come from a variety of ethnic backgrounds including Pakistani and Indian heritages and the proportion of students who speak English as an additional language is higher than the national average. Students come from areas with high levels of social and economic disadvantage and there is a greater than average proportion of students eligible for free meals. There is also an above average number of students with learning difficulties and/or disabilities. Ofsted recently graded the school 'satisfactory' for its overall effectiveness although the sixth form was graded 'outstanding'. The success of the sixth form is one of the reasons why Arvind and Damon wish to study for their A levels there. Both boys intend to study A level mathematics although neither enjoys it.

Deneswood School is a large, 11-18, mixed sex, comprehensive and is a Science, Mathematics and Language college. Of the approximate 1,500 students that attend the school, $60 \%$ are White British and the remaining $40 \%$ are from a variety of ethnic backgrounds. It is a highly successful school with two-thirds of pupils achieving $5+A^{*}-\mathrm{C}$ (including mathematics and English) GCSEs. Standards are well above national averages 
at Key Stage 3 and Key Stage 4 and Ofsted recently described it as 'an outstanding school'. There is a lot of competition from students from this school, and neighbouring ones, to enter the sixth form. The students in the focus group (Affiza, Tim, Andrew, Shakeel and Tariq) are from the top set for mathematics and all state that mathematics teachers continually remind them that they are in 'set one'. Teachers repeatedly express their high expectations of these students and they have all been assured that they will perform well in their Mathematics GCSE and that, if they choose to study A level mathematics, they will be successful. All of the students in the focus group have older siblings that have already progressed to higher education and in most cases their parents had attended university and are now employed in various professional careers. The five students have all chosen A level mathematics as one of their subject choices for sixth form study.

We acknowledge that we are comparing five students from one school that are not intending to take A level mathematics with two and five students from another two schools that do intend to. As cases from within particular case study sites we argue that their decision-making has been influenced by their socially-framed understanding of the relevance of mathematics. We also acknowledge that their attitudes will have been affected by the social capital, cultural capital and economic capital that they bring to the classroom.

\section{Larkstone School}

Although Joe and Nathan have already gained their Mathematics GCSE neither boy is considering mathematics at A level. The following exchange between the two of them highlights several areas of importance as to why mathematics has been disregarded.

[They are sitting in their focus group, in a mathematics classroom, in front of the whiteboard which is covered in mathematical formulae from a previous lesson. Their 
conversation is highly amusing to the rest of the focus group and everyone, including Joe and Nathan, is laughing.]

Joe $\quad$ You look at that and it just looks like Einstein's been here.

Nathan Seriously when am I going to use that when I get a job? When am I going to use that when I get a job?

Joe It's just dead confusing when you look at it. What bit of that do you understand apart from the date?

Nathan Kids like to learn stuff that they're interested in.

Joe You need basic maths but that's just shit.

Nathan I can't really see where we're going to use that in our later life. You go to ASDA, you don't use one of them, do you? You don't take a pen and paper and write all of that, do you?

Joe What's the three point moving average for a tin of baked beans? [laughter from group]

Nathan Like my mum works the till at ASDA and she's the thickest person you'd ever meet. But she works at ASDA. She uses maths but on a calculator thing.

Joe $\quad$ You only need general maths. There's no point in using all of this.

Nathan Cos you only need that if you're gonna like do a proper, complicated job.

Joe $\quad$ Like in the army, bomb-squad, something with computers.

Nathan Or science or summat.

Joe Something that you link with physics.

Nathan $\quad$ You know being a pilot you have to do that for take-off, you have to measure the weight and the thingy with the people and that ...

Joe $\quad$ You mean when there's a bloody war they sit there with calculators!

Nathan $\quad$... that's what they have to do before flying. And that's only adding and taking away ... even a good job like a pilot only uses simple maths. 
Of interest here is the boys' perception of mathematics within the work place because, as Hoyles et al (2002) assert, when focusing on mathematics in the work place, it is essential that workers understand the meaning of mathematics in the context of work. Nathan is aware that his mother does not have a professional job, that she 'works the till at ASDA' but that this job is centred around mathematics although it is 'on a calculator thing' (the till). Nathan argues that his mother 'uses maths', in a job he considers low skilled as his mother is disparagingly described as 'the thickest person you'd ever meet'. The mathematical content is irrelevant to Nathan because technology has superseded the mathematical skills required in order to do the job. Other skills have now become important such as customer service skills and interpersonal skills. Joe and Nathan believe that you only need 'general maths' but Nathan also doubts how much this is needed because he sees that his mother, in her daily life, uses mathematics but always 'on a calculator thing'.

When identifying jobs that they feel would have more demanding mathematical content, they use ambiguous phrases as: 'something that you link with physics'; 'something with computers'; and jobs 'in science or summat'. They name only two jobs they feel are a 'proper, complicated job' - pilot, and working in the bomb-squad in the army. And again, for Nathan, the mathematical content of such jobs is reduced. For a pilot, at take-off, it is a case of 'only adding and taking away' and, again, technology does everything. Jobs require little mathematical knowledge because 'even a good job like a pilot only uses simple maths'.

Having considered their views on mathematics and work we turn to how these two students believe mathematics will be involved within their everyday, adult lives. Nathan queries the relevance of the complex mathematical formulae that is written on the whiteboard by stating that he is unable to determine where it would be useful in later life. We might want to question the assumption that mathematics, or any school subject, or education in general, should be directly useful. 
Within the boys' dialogue they concoct a scenario of visiting a supermarket. Shopping involves many mathematical calculations and financial transactions and this activity can include shoppers mentally totalling prices to ensure they do not exceed a budget. However, Nathan claims that 'you don't take a pen and paper and write all of that' because for him mathematics has been removed from the situation of shopping. Although he is aware that mathematics occurs in shopping (he refers to his mum working the till) he thinks people do not need to worry about the mathematical aspect of shopping because technology does everything. Joe, in turn, asks facetiously, 'What's the three point moving average for a tin of baked beans?', thus demonstrating his awareness of the mathematical concept of time series analysis but considering it irrelevant to everyday life. This is because, as a sixteen year old attending Larkstone school, time series analysis is not directly relevant to his everyday life. And if mathematics lessons are unable to present mathematical concepts in realistic contexts then students like Joe will continue to feel that mathematics is irrelevant to their lives.

For Joe and Nathan technology has advanced to the stage where workers no longer need mathematical skills. Nathan's mother does not need to know how the till works in the supermarket, and the mathematical workings behind it, she just needs to know how to operate it. So although they acknowledge what the till is doing mathematically and know that it performs complicated mathematical functions, they believe workers no longer need to know much mathematics themselves. This is the case for workers in both simple jobs and more advanced jobs. The responsibility for accuracy has been taken away from the user.

Whereas students at other schools (see Deneswood) would regard mathematics as an elite and important subject and would wish to do it at A level because of its status and exchange value, Joe and Nathan's dialogue illustrates the view of students that would acknowledge that there is plenty of mathematics surrounding them in the world (they 
talk of Einstein, mention computers, science and physics) but they do not view it as important. Whilst they know that a student that wishes to become a pilot will need a mathematical qualification to embark upon that career they then believe that once fully trained the pilot will not need to use mathematics on a daily basis because technology has overridden that need. Therefore, they do not perceive mathematics as having great value.

Joe and Nathan appreciate that mathematics is important but it is the level of complexity that causes concern. Joe feels as though 'Einstein's been here' and that the mathematics that is being presented to him is too complex and confusing (he only understands the date when he looks at the whiteboard!). This complexity, which then appears irrelevant, has the capacity to make the students uninterested in the subject and unlikely to pursue it to A level. Joe is aware of mathematics that is embedded in many daily activities although he terms it 'basic maths' or 'general maths' and believes that when it becomes too complicated 'there's no point'. Nathan agrees that students like to learn things 'that they're interested in' so if mathematics could be seen to be relevant to them as individuals and to their future adult lives it would become interesting and therefore worth learning. The boys' disregard for mathematics is a worrying attitude when it is noted that both boys have achieved their Mathematics GCSE a year earlier than most students within the country and have the capability to pursue A level mathematics. Although mathematically competent they disregard this subject partly because it is not perceived to be relevant.

Joe and Nathan's views are not unique and betray deeply held social class positions regarding mathematics, mothers and work. This dialogue arguably could not have happened within a mathematics classroom in some of the other schools in our research sample. The boys' understanding of whether mathematics is important or not, and relevant or not, is tangled up with their view of the world and, in particular, their view of work in the future. Their limited understanding of 'proper, complicated jobs' (forwarding 
very male-oriented jobs which reflect their gendered attitudes) but detailed knowledge of supermarket work will be different from the experiences of students from other social places, and ultimately this will have an influence upon their decision-making with regard to subject choice at A level.

For these and many other students at Larkstone school the relevance of mathematics is its usefulness. Whilst they acknowledge that mathematics is everywhere they do not see its importance because technology will perform any function that they might have needed mathematics for. They know that mathematics is embedded in all forms of technology (supermarket tills, aeroplanes) but feel it is irrelevant to individual workers because any need for mathematical knowledge has been eroded by that very technology. These students also appear to have a limited view on the extent to which technology impacts upon their own everyday life. Although mentioning supermarkets and aeroplanes they fail to identify the technology (based on mathematical functioning) in their own lives.

At Larkstone school one of the mathematics teachers has tried to incorporate real life examples into his mathematics teaching in order to make the work seem relevant to his students. They state:

Leanne He did with the Pythagoras, like the architecture and stuff like that, he told us where it would be useful. And he told us about Alan Titchmarsh or summat, a TV programme or summat.

Kieran And when he was on about marking out stuff on the floor, getting all the angles and stuff like that.

Stuart And loci. If you get a pet and you need to know how far it will go [all laugh]. 
The above dialogue highlights the difficulties inherent in attempting to teach mathematics in a realistic and relevant way. We are not discussing here whether or not teachers should make the curriculum more relevant but rather are interested to explore how student perception of curricular relevance is shaping their attitudes to mathematics. Although the teacher has given some interesting examples Leanne is struggling to recall the mathematical concepts with the examples she has been given. When Stuart relates the episode where they acted out, in the classroom, the distance travelled by a pet goat for the example on loci the students they all laugh. Although they have been told that this is a relevant and realistic example they know that this is not the case because in their lives nobody wants to tie a pet to a post in the garden and work out the distance it may wander.

\section{Chattingham School}

Positive remarks about mathematics came from two boys from Chattingham School. During their focus group they explained to the other members of the group why, although they disliked mathematics, they intended to study it at A level.

Arvind Even if you hate maths you need it 'cause it does make you think.

Damon In maths you do get taught stuff that you don't actually need to learn that you won't use again but it still helps you understand things, what it's about. ... Everything kind of needs maths. Like maths is one of them things that's got basic skills that you can transfer between everything. But almost everything you learn in maths is advancing your logical thinking and you need it.

Arvind Maths is probably my least favourite subject but, if you kind of think of it, like it's logical, isn't it, there's always a right answer.

Damon The skills you learn in maths will help you throughout your life.... The skills learnt in maths are transferable so obviously it allows a lot of opportunities. 
This brief dialogue illustrates our second category of relevance: that of transferable (process) skills. This discourse is not simply their own understanding as it is reflected in other focus group conversations with the students and head of department. The idea of developing transferable skills - mathematics as a way of thinking - is central to the departmental philosophy. These two students view mathematics as being useful for problem solving. In contrast to the focus group students from Larkstone (above) and Deneswood (below) they do not see it primarily as being relevant to the workplace or to everyday life, of having exchange value or usefulness. Rather the relevance of mathematics is in a way of thinking logically that enables one to solve problems (whether functional or not) in a range of contexts and therefore having widespread usefulness.

\section{Deneswood School}

This school has a population that is ethnically diverse, middle-classed and largely professional. The five students in the focus group aspire to professional occupations such as vet, doctor and surgeon.

The following dialogue is their discussion of the relevance of mathematics in careers, why they themselves have selected mathematics as an A level subject and how they believe it will fit into their future proposed careers.

Affiza Like if you're going to be like a hairdresser then maybe you won't be motivated by maths because it's not really critical to your career ...

Tim Depending on your career.

Affiza $\quad .$. like if you're going to be a pilot. It's different for different people, because like from maths you go into accountancy and things like that, I think. But it's like not everyone needs it. 
Andrew My friend has a friend who's a joiner and he was building something and Pythagoras, he suddenly came up with, and he's not like the cleverest of people and he suddenly just came up with Pythagoras out of nowhere and he just sort of shocked everyone cause he was building something.

Tim In all the careers, it's always maths. You always need maths.

Shakeel As a back-up.

Tim For nearly all the careers you need maths.

Andrew Cos like I'm doing music, cause I want to do music, but then maths and physics and stuff, it's like a back-up. And like most places or jobs you go to they say 'have you got a maths degree?' For better jobs.

Affiza That woman ... she had just come out of university ... with physics ... and she was like 'most people don't do anything that is related to their degree, they do maths instead, they go and do accounting or something'. So like everyone uses maths as a back-up. ... I picked them [subject choices] because I just thought they're all quite academic and I definitely need maths and chemistry to go into medicine.

Tim I want to be a vet. If I don't get the grades then I can always go into something else cause like all my teachers are saying that it will open doors rather than close them.

Shakeel [wants to be a surgeon] You can choose which university course you want to do if you do three sciences and maths.

Tariq [wants to be a computer programmer] Maths and physics are good together and like as a back-up and you need some maths in programming.

Further comments from the focus group revealed the influence of parents upon proposed careers - albeit different from those at Larkstone - and this is an important factor to consider. The students are from professional families where parents understand the gatekeeping function of mathematics (Skovsmose, 1998; Volmink, 1994) for access to professional occupations and this is particularly the case for Asian parents who have 
marked ambitions for their children. These views are continually reinforced by the school both formally and informally through the peer group.

It can be seen that mathematics, and more importantly a mathematics qualification, is viewed as relevant and important to these students. Affiza deliberately chooses subjects that are considered 'academic', and Shakeel believes that qualifications in biology, chemistry, physics and mathematics will permit entry into both the university and course of his choice. Both he and Tim believe that these subjects will 'open doors' and, along with Tariq, view mathematics as being a complementary subject to the science subjects. They view mathematics as having great exchange value as they claim that mathematics is needed in 'nearly all careers' and 'for better jobs'.

The students at Deneswood school view mathematics as performing another important function - that of providing contingency should careers not go to plan. Mathematics is something that can be used as a 'back-up', a kind of trump card, should a career in music not materialise or the grades are not obtained for entry on to a veterinary science course. In addition, as highlighted by Affiza's comments about a visitor to the school, even if another discipline is studied at degree level any mathematical content can be used towards another career, thus a degree in physics will permit a career in accountancy.

It is argued that adults with an A level in mathematics earn higher salaries (Wolf, 2002) and it is interesting to note how Affiza views mathematics as being an academic subject that leads to professional jobs. It is professional jobs where mathematics is required because she argues that mathematics is 'not critical' to a hairdresser's career but that it would lead to jobs in aviation, accountancy and medicine. However, Andrew introduces the concept of a joiner using Pythagoras in his work and how this shocked his colleagues. Although the students believe that mathematics is essential to their future careers they do tend to hold limited views of the types of careers that would involve 
mathematics. Mathematics is clearly linked to the professional jobs that they aspire to but not so to the jobs that students at Larkstone School would aspire to in their working class community.

From the analysis of the dialogue between the Deneswood school students, we see a difference in the meaning of the word relevant. For these students the relevance of mathematics is in its exchange value. A mathematics qualification permits entry on to a desired course at a desired university, it provides contingency in the form of a 'back-up' should proposed careers not happen and it helps gain access into a high powered, professional occupation. A mathematics qualification has currency because it demonstrates that the holder is clever because they are good at mathematics which is a different perspective from the one held by the Chattingham school students who believe that the relevance of mathematics is in providing transferable skills. Interestingly, also, the Deneswood school students do not have the same critical perspective as the Larkstone boys regarding the embedded nature of mathematics. Mathematics is a power subject giving access to higher paid careers and economic security. This discourse (of the middle classes and their teachers) seems to go largely unchallenged. They can become the controllers of the mathematised world that they aim to inherit.

\section{Discussion}

The above analysis suggests that students with similar mathematical potential but from different schools interpret the relevance of mathematics differently. The three schools are located in different social contexts and the students from these three schools perceive mathematics in different ways, although we are not presuming that views are homogeneous within one school, or one social group. For the students at Larkstone the word relevance indicates practical usefulness in the daily work and living. Although they recognise the pervasiveness of mathematics in the world and in the work place it is not important to them as learners because of ubiquitous mathematical technologies. This has implications for teaching mathematics at this school because these students believe that 
mathematics is not really worth anything when put into the context of working the till at ASDA or being a pilot. Therefore, teachers are faced with the challenge of demonstrating how mathematics could be included within the work place. But this is a problem since we know that mathematics in context can look very different from mathematics in the school classroom. Our short excerpt from Chattingham School shows students who perceive relevance as being transferable process skills. Although mathematics might have usefulness as exchange value they perceive it to be a more useful set of transferable skills, ways of thinking about problems and of problem solving. Interview and observation data suggests that this school approaches its mathematics teaching with an emphasis on developing mathematical thinking, problem solving and modelling. At Deneswood school mathematics lessons are more transmission focused, with student motivation (amongst the high attainers at least) arising from this sense that mathematical success should assure them entry into professional occupations. Teachers at this school are also aware that parental influence and pressure will lead to many students selecting mathematics and science subjects at A level.

We have considered school context and school approach in these and the other schools in the study and suggest that these influence the type of mathematical experiences that students have. The notion of relevance varies based on the school attended and the social context. In some schools the approach of the school seems to better match the notion of relevance held by the students. We offer the three categories of practical usefulness (Larkstone); transferable process skills (Chattingham) and professional exchange/entry value (Deneswood). We have to bear in mind that we have been focusing on the marginal students that are capable of A level mathematics who might/might not study it. If we had focused on very high attaining students we expect that we would have found more students claiming relevance as exchange value, and if we had focused on lower attainers we might have found more claiming relevance meant usefulness. Indeed our three categories reflect Ernest's (1992) groups contesting the original mathematics National Curriculum: 'old humanists' (those in the academy), 
'industrial trainers' (the employers) and the 'progressive educators'. Respectively we might draw links from these groups to professional, practical and process relevance although the correspondence is not ideal.

As relevance means different things to different students we suggest that teachers need to be mindful of these variations and, being more critically aware of multiple aims for the curriculum (Noyes, 2007), should teach accordingly. This means that relevance as practical usefulness at Larkstone, relevance as transferable process skills at Chattingham and relevance as professional exchange value at Deneswood School should explicitly frame curriculum and pedagogy. A singular emphasis might act to reinforce the social divide between different types of student. Indeed there appears to be a sociological principle here not dissimilar to that explored by Cooper and Dunne (2000). Their work showed that an emphasis on realism (which although not the same as relevance is related) in assessment actually disadvantages those students without the same type of cultural capital as educators and test writers. Such capital is required to understand that apparently realistic contexts are mere façades for abstract mathematical problems. Without this (socially inherited) key insight too much is made of the context and the student does not do the mathematics as required by the controllers of the assessment system. We see in our data a similar trend. At Larkstone a particular effort is being made to make the curriculum relevant. The students then draw upon their reasonable understanding of a mathematised world to conclude that what they are told in lessons is not actually the case in reality. In contrast, for the student focus group at Deneswood practical relevance is not a critical issue since they are endowed with the kinds of capital (Reay, 2004) which steers them towards elite courses, institutions and careers. They have an embodied sense of the cultural exchange value of mathematics qualifications. They are the inheritors of the powerful positions of the future and mathematics is the entry ticket. As Andrew explains: "most places or jobs you go to they say 'have you got a maths degree?'...for better jobs". 
We conclude that mathematics education should enable all students, from whatever social background, to understand the formatting role of mathematics (Skovsmose, 1994) and acquire the critical awareness of how mathematics works in, and is worked on, society. This is the task of the fourth of Ernest's categories - the 'public educator'. A fourth dimension of relevance, which we call political relevance is missing in our data and needs development in a mathematics education fit for an inclusive $21^{\text {st }}$ century society. Such political relevance has been the preserve of critical mathematics educators (e.g. Gutstein, 2006; Skovsmose, 1998) but there is a need for mathematics educators in England to reconsider how such might be incorporated into the curriculum (Noyes, 2009).

\section{References}

Cooper, B., \& Dunne, M. (2000). Assessing Children's Mathematical Knowledge: social class, sex and problem solving. Buckingham: Open University Press.

Ernest, P. (1992). The National Curriculum in Mathematics: Political Perspectives and Implications. In S. L. a. M. Nickson (Ed.), The Social Context of Mathematics Education: Theory and Practice (pp. 33-61). London: South Bank Press.

Ernest, P. (2004). Relevance versus Utility: some ideas on what it means to know mathematics. In D. C. B. Clarke, G. Emanuelssonet al (Ed.), Perspectives on Learning and Teaching Mathematics (pp. 313-327). Goteborg: National Centre for Mathematics Education.

Gellert, U., \& Jablonka, E. (Eds.). (2008). Mathematisation and Demathematisation Rotterdam: Sense Publishers.

Gutstein, E. (2006). Reading and Writing the World with Mathematics: Toward a Pedagogy for Social Justice. New York: Routledge.

Hoyles, C., Wolf, A., Molyneux-Hodgson, S., \& Kent, P. (2002). Mathematical Skills in the Workplace, Final Report to the Science, Technology and Mathematics Council.

Lave, J., \& Wenger, E. (1991). Situated Learning: legitimate peripheral participation. Cambridge: Cambridge University Press.

Musto, G. (2008). Showing you're working: a project using former pupil's experiences to engage current mathematics students. Teaching Mathematics and its Applications, 27(4), 210-217. 
Noyes, A. (2007). Mathematics Counts...for what? Rethinking the mathematics curriculum in England. Philosophy of Mathematics Education, 21.

Noyes, A. (2009). Participation in Mathematics: what is the problem? Improving Schools, 12(3), 277-299.

Noyes, A., Wake, G., Drake, P., \& Murphy, R. (2009). Evaluating Mathematics Pathways: Stage 6 report, December 2009 (confidential report to QCDA). Nottingham: University of Nottingham.

Onion, A. (2004). What use is maths to me? A report on the outcomes from student focus groups. Teaching Mathematics and its Applications, 23(4), 189-194.

Reay, D. (2004). Education and Cultural Capital: the implications of changing trends in education policies. Cultural Trends, 13(2), 73-86.

Skovsmose, O. (1994). Towards a philosophy of critical mathematics education. Dordrecht: Kluwer Academic Publishers.

Skovsmose, O. (1998). Linking Mathematics Education and Democracy: Citizenship, Mathematical Archeology, Mathemacy and Deliberative Action. Zentralblatt für Didaktic der Mathematik/International Reviews on Mathematics Education, 30(6), 195-203.

Volmink, J. (1994). Mathematics By All. In S. Lerman (Ed.), Cultural Perspectives on the Mathematics Classroom (Volume 14 ed.). Dortrecht: Kluwer Academic Publishers. Wilson, V. (1997). Focus Groups: a useful qualitative method for educational research. British Educational Research Journal, 23(2), 209-224. 